\title{
ANÁLISE DA CORRELAÇÃO ENTRE RESISTÊNCIA À COMPRESSÃO E A VELOCIDADE DE PROPAGAÇÃO DO PULSO ULTRASSÔNICO DE CONCRETOS COM ADITIVO SUPERPLASTIFICANTE E METACAULIM
}

\author{
HENRIQUES RABELO GOUVÊA, GABRIEL \\ Engenheiro Civil \\ Universidade FUMEC \\ Minas Gerais - Brasil \\ Gabrielhrg.ep@gmail.com
}

\author{
ILCE ROCHA PERDIGÃO, NATHÁLIA \\ Engenheira Civil \\ Universidade FUMEC \\ Minas Gerais - Brasil \\ nathaliaperdigao@hotmail.com
}

\author{
SOARES DO NASCIMENTO, KAMILA \\ Engenheira de Produção/Civil \\ Universidade FUMEC \\ Minas Gerais - Brasil \\ kamilasoaresn@gmail.com
}

\author{
FREITAS AZEVEDO, PATRÍCIA \\ Engenheira Civil \\ Universidade FUMEC \\ Minas Gerais - Brasil \\ azevedo.freitas.patricia@gmail.com
}

\section{RESUMO}

O concreto vem sendo objeto de vários estudos e pesquisas no intuito de melhorar suas propriedades, visando uma maior durabilidade e eficiência. Além disso, a manutenção e recuperação das obras civis tem ganhado destaque, uma vez que, manter estruturas em funcionalidade é economicamente mais viável. Na prática, é sabida a dificuldade de realização de ensaios destrutivos. Tendo em vista essa demanda, desenvolveu-se o presente trabalho para verificar a correlação dos resultados do ensaio não destrutivo de ultrassom e do ensaio destrutivo de compressão axial. Nesta pesquisa foram estudados três grupos de concretos, todos com o mesmo traço 1:2,5:3. Os corpos de prova (CPs) de referência foram moldados utilizando cimento portland, agregados e água. No segundo grupo foram adicionados $20 \mathrm{~g}$ de aditivo superplastificante. No terceiro grupo, além do aditivo, houve acréscimo de Metacaulim em $1 \%$ sobre a massa de cimento. Os CPs foram aferidos em suas dimensões e massas nas idades de 7, 14, 21 e 28 dias. Também foram realizados ensaios de ultrassom nos dias 14, 21 e 28, sendo que na última idade, os CPs foram submetidos ao ensaio de compressão axial. Através da análise dos ensaios, constatou-se que o concreto com Metacaulim apresentou os maiores valores e provou-se que o ensaio de ultrassom pode ser utilizado como ferramenta de medida indireta da resistência do concreto. Logo, por se tratar de um ensaio de menor complexidade e impactos à estrutura, o ultrassom é recomendado para a aferição de resistência à compressão axial e poderá auxiliar no diagnóstico precoce de patologias, possibilitando uma maior durabilidade das estruturas.

Palavras-chave: concreto, ultrassom, ensaio não destrutivo, compressão axial, aditivos.

\begin{abstract}
The concrete has been the object of several studies and researches in order to improve and enhance its features, aiming a higher durability and efficiency. In addition, the maintenance and restoration of civil works has gained prominence, since maintaining structures in functionality is more economically viable. In practice, the difficulty of conducting destructive testing is known. In view of this demand, the present work was developed to verify the correlation between the results of the non destructive ultrasound test and the destructive axial compression test. Three groups of concrete were studied in this research, all with the same trace, being 1:2,5:3. The first group specimens were shaped as reference, with the use of portland cement, aggregates and water. In the second group, $20 \mathrm{~g}$ of superplasticizer additives were added. In the third group, besides the additive, there was the addition of $1 \%$ over cement mass of Metakaolin. The specimens were assessed in their measurements and masses in the ages of 7, 14, 21 and 28 days. Ultrasound tests were also performed on days 14, 21 and 28, and at the last age, the specimens were submitted to the axial compression test. Through the tests analysis, it was found that the concrete with Metakaolin presented the highest values and it was proved that the ultrasound test can be used as an indirect measurement tool of the concrete strength. Therefore, because it is a less complex and impactful test, ultrasound is recommended for the measurement of resistance to axial compression and may help in the early diagnosis of pathologies, allowing a greater durability of the structures.
\end{abstract}

Keywords: concrete, ultrasound, non destructive test, axial compression, additives. 


\section{INTRODUÇÃO}

A indústria do concreto está em constante evolução para elaborar concretos de melhores características. E apesar dos constituintes básicos do concreto não terem se modificado muito nos últimos 30 anos, a não ser o uso de aditivos para lhe conferir propriedades especiais, sua tecnologia evoluiu significativamente com o avanço do conhecimento da microestrutura da pasta e, principalmente, da interface como agregado. Os equipamentos de produção foram aperfeiçoados para produzir misturas mais homogêneas, além de facilitar a colocação e compactação (MEDINA, 2011).

A crescente evolução das tecnologias empregadas na construção civil é representada pelo grande número de pesquisas dedicadas a melhorar o desempenho dos materiais utilizados. O concreto pode ser de grande importância nesse meio, pela simplicidade de sua composição (cimento, areia, brita e água), baixo custo e fácil obtenção de seus componentes, além da possibilidade de incorporação em sua massa de diversos materiais (GASPARIN, 2017).

O controle de qualidade e resistência do concreto é normalmente realizado através de ensaios destrutivos de compressão, método eficiente para verificar se a resistência requerida em projeto foi atendida. Porém, como cita Mohamad et. al (2015), em estruturas já executadas o método se torna tecnicamente inviável, devido à grande dificuldade de extração de testemunhos ou corpos de prova em tamanhos requeridos por norma e ao transtorno causado aos usuários da edificação.

Neste âmbito, torna-se fundamental o desenvolvimento e estudo de ensaios não destrutivos, como o de propagação de ondas ultrassônicas, para analisar a qualidade e resistência do concreto, aprimorando assim as técnicas de avaliação de estruturas já edificadas e permitir a detecção de possíveis patologias existentes nas mesmas.

\section{REFERENCIAL TEÓRICO}

\subsection{Concreto}

As principais características do concreto são plasticidade quando fresco, resistência mecânica e durabilidade, quando endurecido. A obtenção de uma massa de concreto que atenda tais características só é possível com um adequado dimensionamento dos componentes e com o conhecimento das influencias que a característica de cada um tem sobre a mistura, é nesse princípio que se enquadra a dosagem do concreto (GASPARIN, 2017).

\subsection{Cimento Portland}

Os cimentos CP II são ditos compostos pois apresentam, além da sua composição básica (clínquer+gesso), a adição de outro material. O CP II gera calor numa velocidade menor do que o gerado pelo Cimento Portland Comum (CP I). Seu uso, portanto, é mais indicado em lançamentos maciços de concreto, onde o grande volume da concretagem e a superfície relativamente pequena reduzem a capacidade de resfriamento da massa. Este cimento também apresenta melhor resistência ao ataque dos sulfatos contidos no solo. Recomendado para obras correntes de engenharia civil sob a forma de argamassa, concreto simples, armado e protendido, elementos pré-moldados e artefatos de cimento. A aceitação e o uso desse tipo de cimento expandiu-se nos últimos anos e nos dias atuais, cerca de $58 \%$ de todo o cimento consumido no Brasil é do tipo composto, seja ele E, F ou Z.

\subsection{Aditivos e Adições}

Os aditivos superplastificantes são também chamados de aditivos redutores de água de alta eficiência, porque são capazes de reduzir de três a quatro vezes a água de amassamento em uma determinada mistura de concreto, se comparado aos aditivos redutores de água normais. $\mathrm{O}$ aumento das propriedades mecânicas de resistência à compressão e à flexão são normalmente proporcionais à redução na relação água/cimento. Devido a maior velocidade de hidratação do cimento no sistema bem disperso com o uso do aditivo, as misturas de concreto que têm superplastificantes apresentam resistências à compressão ainda maiores a um, três e sete dias comparando com o concreto referência (MEHTA e MONTEIRO, 2008).

Sabe-se que a incorporação de adições minerais em geral resulta na produção de materiais cimentícios com melhores características técnicas, uma vez que modificam a estrutura interna do concreto no estado fresco. Essas adições trazem diversos benefícios que aumentam a durabilidade e resistência do concreto no estado endurecido, como: redução na 
porosidade capilar, diminuição das fissuras de origem térmica, melhoria na resistência a ataque por sulfatos, melhoria na resistência a reação álcali-sílica, entre outros (MORAES, 2014).

O Instituto Brasileiro de Impermeabilização (IBI, 2015), define em seu manual de aditivos para concreto que, a aplicação de plastificante e superplastificante confere vantagens ao concreto. O aumento da consistência, onde sem adicionar mais água tem-se um ganho na fluidez do concreto, o aumento da resistência, uma vez que para reduzir o consumo de água basta manter fixo o consumo de cimento e a consistência. Ainda se for a necessidade reduzir o consumo de cimento, basta dosar o aditivo de forma a reduzir a relação a/c sem que isso altere a consistência.

O metacaulim é uma adição constituída basicamente de sílica $\left(\mathrm{SiO}_{2}\right)$ e aluminia $\left(\mathrm{Al}_{2} \mathrm{O}_{3}\right)$ na fase amorfa. O metacaulim é capaz de reagir com o hidróxido de cálcio, $\mathrm{Ca}(\mathrm{OH}) 2$, gerado durante a hidratação do cimento Portland e formar produtos hidratados similares aos decorrentes da hidratação direta do clínquer Portland. Em presença do metacaulim, durante a hidratação do cimento Portland, formam-se silicatos de cálcio hidratados que melhoram a resistência e a durabilidade das pastas, argamassas e concretos no estado endurecido. O resultado é um material cimentício com menor quantidade de clínquer e, consequentemente, menor consumo de energia e menor emissão de dióxido de carbono, $\mathrm{CO}_{2}$ (MENEZES, 2006).

\subsection{Velocidade de Propagação de Onda Ultrassônica em Concretos}

As primeiras publicações sobre medições de velocidade de pulsos mecanicamente gerados apareceram no Estados Unidos em meados de 1940. Constatou-se que a velocidade de propagação se relaciona com a densidade e as propriedades elásticas do material (Pereira e Medeiros, 2012).

O método consiste em medir eletronicamente a velocidade e o tempo de percurso da onda através do concreto, entre o emissor e o receptor. As descontinuidades, também chamados de vazios no interior do concreto, podem ser detectados devido às diferenças de velocidade de propagação de ondas (Mehta e Monteiro, 2014).

Por tratar-se de um método de ensaio não destrutivo, possibilita a avaliação de estruturas sem gerar quaisquer tipo de danos aos elementos estruturais. Segundo Soeiro et. al (2018) e Costa (2004), são diversas as aplicações do ensaio de ultrassom em estruturas de concreto, como a análise da homogeneidade, o monitoramento de variações, a detecção de falhas na concretagem (nichos) e a avaliação de profundidade de fissuras ou outras anormalidades. Costa (2004) ainda cita como o ensaio não destrutivo de ultrassom fornece meios para correlacionar a velocidade do pulso com a resistência à compressão do concreto de corpos de prova e estruturas executadas.

Haach e Ramirez (2016) citam o ensaio de ultrassom como uma poderosa ferramenta de aferição da homogeneidade do concreto, bem como a detecção de heterogeneidades. Os autores apresentam ainda um método de tomografia por ultrassom que permite o mapeamento interno de um corpo de concreto pela execução de diversas medidas em diferentes pontos do corpo. Evidenciam ainda fatores como a densidade da estrutura ensaiada, que afetam diretamente a propagação de ondas ultrassônicas, quanto mais denso e de melhor qualidade o concreto, maior a velocidade de propagação da onda.

\section{MATERIAIS E MÉTODOS}

O programa experimental consistiu em uma matriz de concreto referência e outras duas matrizes de concreto, uma com adição de aditivo superplastificante, e outra com adição de aditivo superplastificante e adição de mineral metacaulim. Os concretos foram produzidos nas mesmas condições e moldados corpos de prova para realização dos ensaios de determinação de massa específica, ultrassonografia e resistência à compressão axial.

Para a produção de concreto foram utilizados cimento Portland CP II-E-32 como aglomerante, areia média natural como agregado miúdo, brita como agregado graúdo, metacaulim como adição mineral, utilizado na substituição de parte de cimento Portland e aditivo superplastificante. Foram elaborados 3 traços para ensaios, sendo o $1^{\circ}$ traço de referência, 1:2,5:3,0 (cimento, areia e brita), $2^{\circ}$ traço 1:2,5:3,0 (cimento, areia e brita) com adição de aditivo superplastificante na proporção de $1,0 \%$ em relação a massa do cimento e o $3^{\circ}$ traço, 1:2,5:3,0 (cimento, areia e brita), teve a adição de metacaulim, na proporção de $1,0 \%$ e adição de aditivo superplastificante na proporção de $0,6 \%$, ambos, em relação ao peso do cimento 
A fim de se obter as características físicas, geométricas e mecânicas dos corpos de prova (CPs) e estudar a possibilidade de correlação entre ensaios, lançou-se mão de três métodos amplamente utilizados para caracterização de CPs de concreto: a medição e pesagem dos CPs para determinação de massa específica, o ensaio não destrutivo da velocidade e tempo de propagação de onda ultrassônica e o ensaio de compressão axial. Todas as medições foram realizadas aos 7 , 14, 21 e 28 dias, o ensaio de propagação de onda ultrassônica aos 14, 21 e 28 dias e o ensaio de compressão axial aos 28 dias.

\subsection{Ensaios Realizados}

\subsubsection{Determinação da velocidade de propagação de onda ultrassônica}

Este método de ensaio não destrutivo é prescrito pela Norma NBR 8802 - Concreto endurecido - Determinação da velocidade de propagação de onda ultrassônica (ABNT, 2013) e tem como principais finalidades a verificação da homogeneidade do concreto, a detecção de eventuais falhas internas de concretagem, profundidade de fissuras e outras imperfeições e monitoramento de variações no concreto, ao longo do tempo, decorrentes de agressividade do meio principalmente pela ação de sulfatos.

Para realização do ensaio de onda ultrassônica, faz-se necessário que as superfícies opostas dos CPs estejam limpas, secas, planas (lisas) e íntegras, processo feito por retificadora de corpos de prova. Além disso, antes da utilização do equipamento de emissão de ondas ultrassônicas, o mesmo precisa ser calibrado com o bloco de calibração e instruções fornecidas pelo próprio fabricante.

O equipamento utilizado neste trabalho foi o Pundit $\mathrm{Lab}(+)$ da proceq, e as medições foram feitas utilizando transmissão direta (figura 03), com os transdutores posicionados em faces opostas, pois desta forma as ondas são recebidas com maior intensidade (NBR 8802, 2013).

Seguindo os procedimentos da NBR 8802 (ABNT, 2013), foram medidos o tempo e a velocidade de percurso do pulso ultrassônico em cada CP estudado, o que possibilita avaliar e comparar a qualidade de cada tipo de concreto moldado pela sua compacidade interna, através dos parâmetros estabelecidos por Whitehurst (1966) e Rincon et al (1998), ilustrados na tabela 01 .

Tabela 01 - Classificação quanto à qualidade do concreto por velocidade de onda ultrassônica

\begin{tabular}{cc}
\hline Velocidade da Onda Ultra-sônica $(\mathrm{m} / \mathrm{s})$ & Qualidade do Concreto \\
\hline $\mathrm{V}>4500$ & EXCELENTE \\
\hline $3500<\mathrm{V}<4500$ & ÓTIMO \\
\hline $3000<\mathrm{V}<3500$ & BOM \\
\hline $2000<\mathrm{V}<3000$ & REGULAR \\
\hline $\mathrm{V}<2000$ & RUIM
\end{tabular}

Fonte: Whitehurst (1966) e Rincon et al (1998).

O índice de vazios do concreto está inversamente ligado à velocidade de propagação das ondas ultrassônicas no mesmo, ou seja, quanto mais poroso, mais lenta a propagação de ondas ultrassônicas e, consequentemente, pior a qualidade. Já a resistência à compressão do concreto está diretamente ligada à velocidade, sendo assim, quanto maior a velocidade de propagação das ondas, mais denso é o concreto e maior sua resistência à compressão axial. Também é indicado o cuidado especial com as superfícies do concreto, a fim de conservá-la lisa e limpa, objetivando o perfeito transutor na peça ou estrutura. Deve-se evitar superfícies muito rugosas ou que tenham recebido algum tipo de acabamento, pois a camada acrescentada não é necessariamente a mesma do seu interior.

Outro fator interveniente na velocidade de propagação da onda ultrassônica em um CP de concreto é o tipo de agregado utilizado para moldagem (MEDEIROS, 2007). Segundo Naik, Malhotra e Popovics (2004), diversos pesquisadores concluíram que a velocidade de propagação de ondas ultrassônicas varia com as características dos agregados graúdos. Ainda assim, percebe-se o padrão de que quanto maior a velocidade, maior a resistência à compressão, como mostrado na figura 02 . 


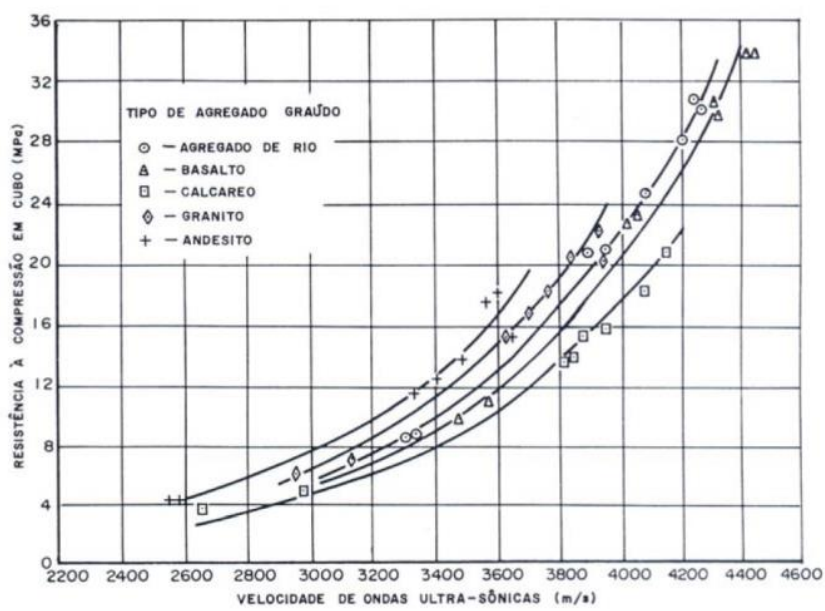

Figura 02 - Correlação entre a resistência à compressão e o ultrassom em concretos com diferentes tipos de agregados graúdos

Fonte: Facaoaru (1961) apud Hamassaki (1986).

\subsubsection{Resistência à compressão axial}

O ensaio de compressão axial é o método mais utilizado para a caracterização do concreto, por ser amplamente difundido e compreendido, além de simples, rápido e eficiente na obtenção dos resultados desejados.

Este método de ensaio destrutivo é prescrito pela Norma NBR 5739 - Concreto - Ensaio de compressão de corpos de prova cilíndricos $(A B N T, 2018)$ e tem como finalidade a determinação da resistência à compressão de corpos de prova moldados conforme a NRB 5738 (ABNT, 2016).

Assim como no ensaio de propagação de ondas ultrassônicas, os CPs devem estar limpos, secos e com suas superfícies opostas planas, íntegras e centralizadas em relação ao equipamento, de forma a garantir que o eixo de aplicação da carga (eixo da máquina) coincida com o eixo do $\mathrm{CP}$. O equipamento utilizado neste ensaio foi uma prensa Emic, a qual atende todos os requisitos prescritos pela norma NBR 5739 (ABNT, 2018), e os corpos de provas foram todos ensaiados com uma idade de 28 dias.

Os CPs são colocados e ensaiados um a um no equipamento, como ilustra a figura 05. Programa-se a máquina para a aplicação de carga na velocidade constante de $0,45 \mathrm{MPa} / \mathrm{s}$ durante todo o ensaio, como determinado por norma. $\mathrm{O}$ carregamento cessa quando houver uma queda de força que indique a ruptura do $\mathrm{CP}$ e obtém-se, para cada um deles, os valores característicos da carga e da tensão de ruptura, bem como as curvas tensão x deformação.

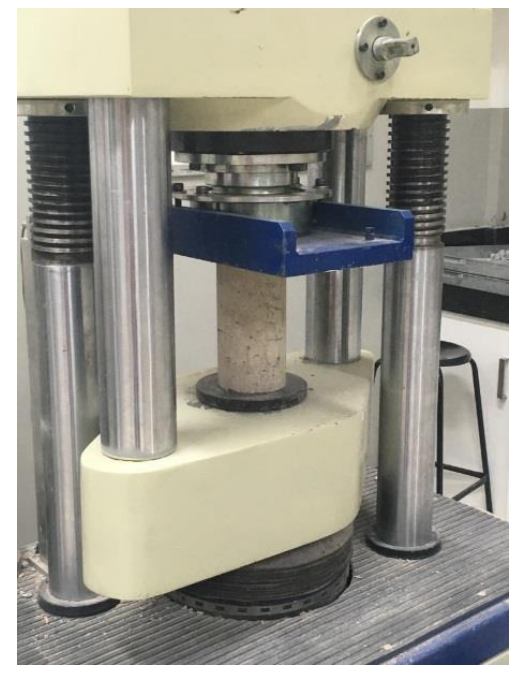

Figura 03 - CP na prensa, antes do ensaio Fonte: Autores (2019). 


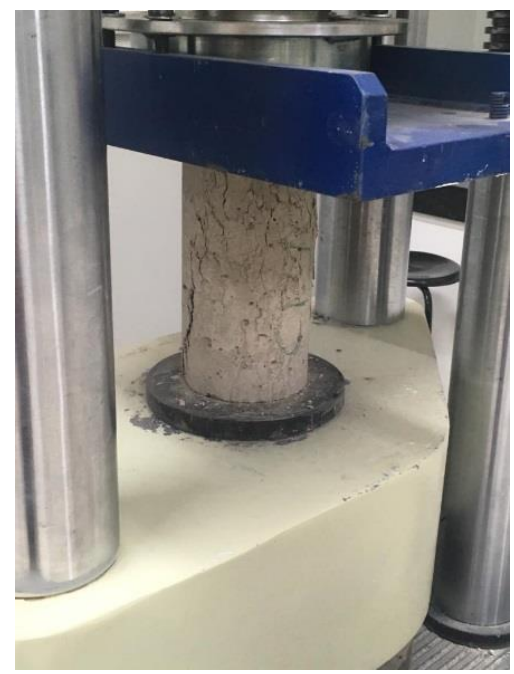

Figura 04 - CP na prensa, após a ruptura Fonte: Autores (2019).

Como já foi dito anteriormente, a resistência à compressão tem relação direta com a massa específica e a velocidade de propagação de ondas ultrassônicas no $\mathrm{CP}$ ensaiado. Portanto, dispondo dos resultados dos três ensaios descritos acima, tem-se boas fontes de caracterização, análise e comparação dos concretos e dos ensaios, objetos de estudo desse trabalho.

\section{RESULTADOS E DISCUSSÕES}

\subsection{Ensaio de ultrassom}

No final dos vinte e oito dias as maiores velocidades de ultrassom foram dos CP's com Metacaulim, seguido do grupo com aditivo, como demonstrado nos gráficos 01,02 e 03 e tabela 02.

Tabela 02 - Comparativo evolução das velocidades da onda

\begin{tabular}{c|c|c|c}
\hline Corpo de Prova & $\begin{array}{c}\text { Velocidade da onda de } \\
\text { ultrassom 14 dias (m/s) }\end{array}$ & $\begin{array}{c}\text { Velocidade da onda de } \\
\text { ultrassom 21 dias (m/s) }\end{array}$ & $\begin{array}{c}\text { Velocidade da onda de } \\
\text { ultrassom 28 dias (m/s) }\end{array}$ \\
\hline CP IA referência & 1996,00 & 2074,00 & 4320,00 \\
\hline CP IIA referência & 2004,00 & 2021,00 & 4228,00 \\
\hline CP IIIA referência & 1992,00 & 2030,00 & 4255,00 \\
\hline CP 1B aditivo & 2241,00 & 2251,00 & 4728,00 \\
\hline CP 2B aditivo & 2179,00 & 2199,00 & 4556,00 \\
\hline CP 3B aditivo & 2189,00 & 2199,00 & 4662,00 \\
\hline CP 1C - Metacaulim & 4484,00 & 4525,00 & 4772,25 \\
\hline CP 2C - Metacaulim & 4515,00 & 4545,00 & 4816,35 \\
\hline CP 3C - Metacaulim & 4484,00 & 4556,00 & 4772,25 \\
\hline
\end{tabular}

Fonte: Os autores (2019). 


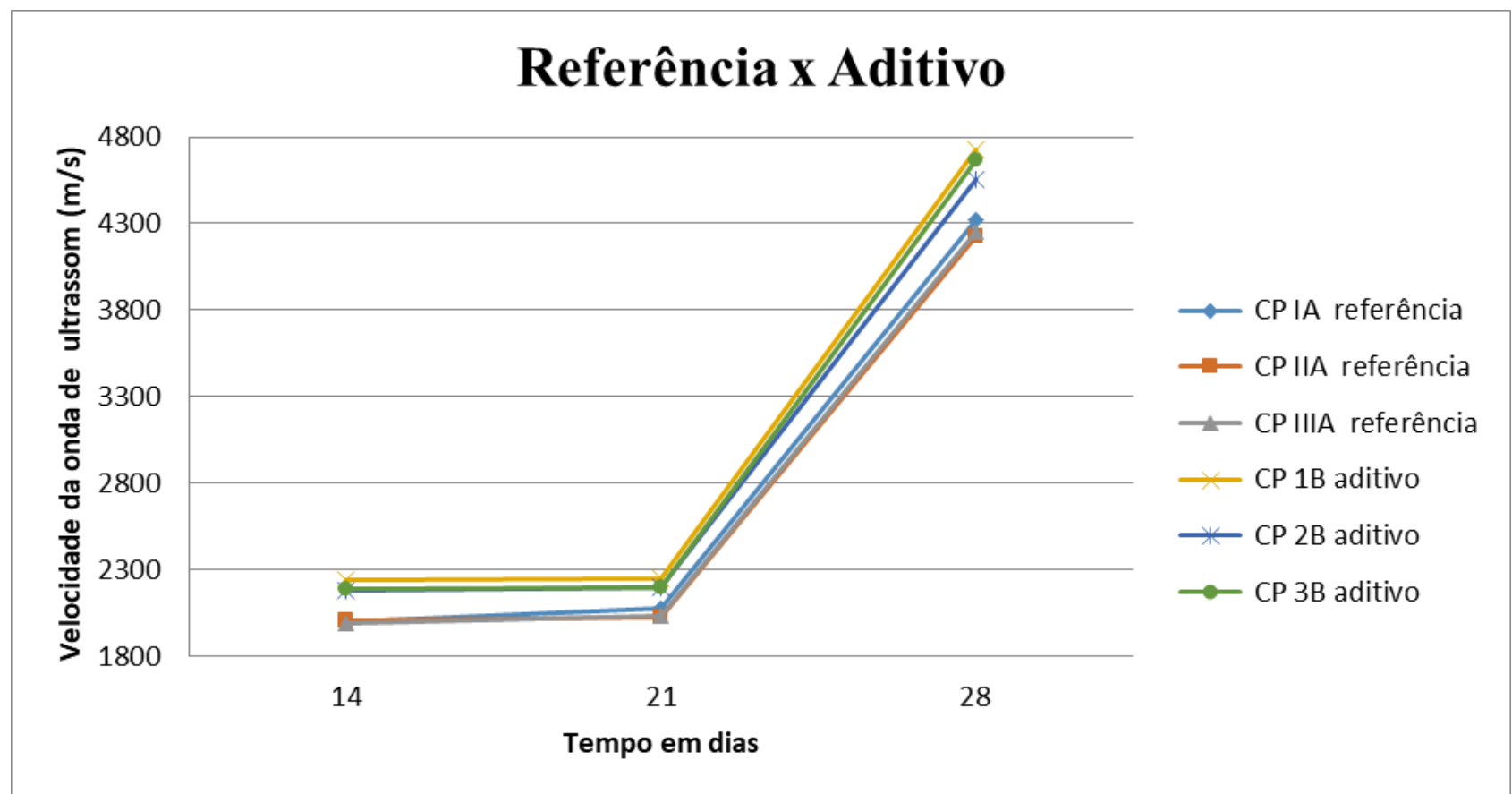

Gráfico 01 - Velocidade da onda de ultrassom x tempo dos corpos de referência e com aditivo

Fonte: Os autores (2019).

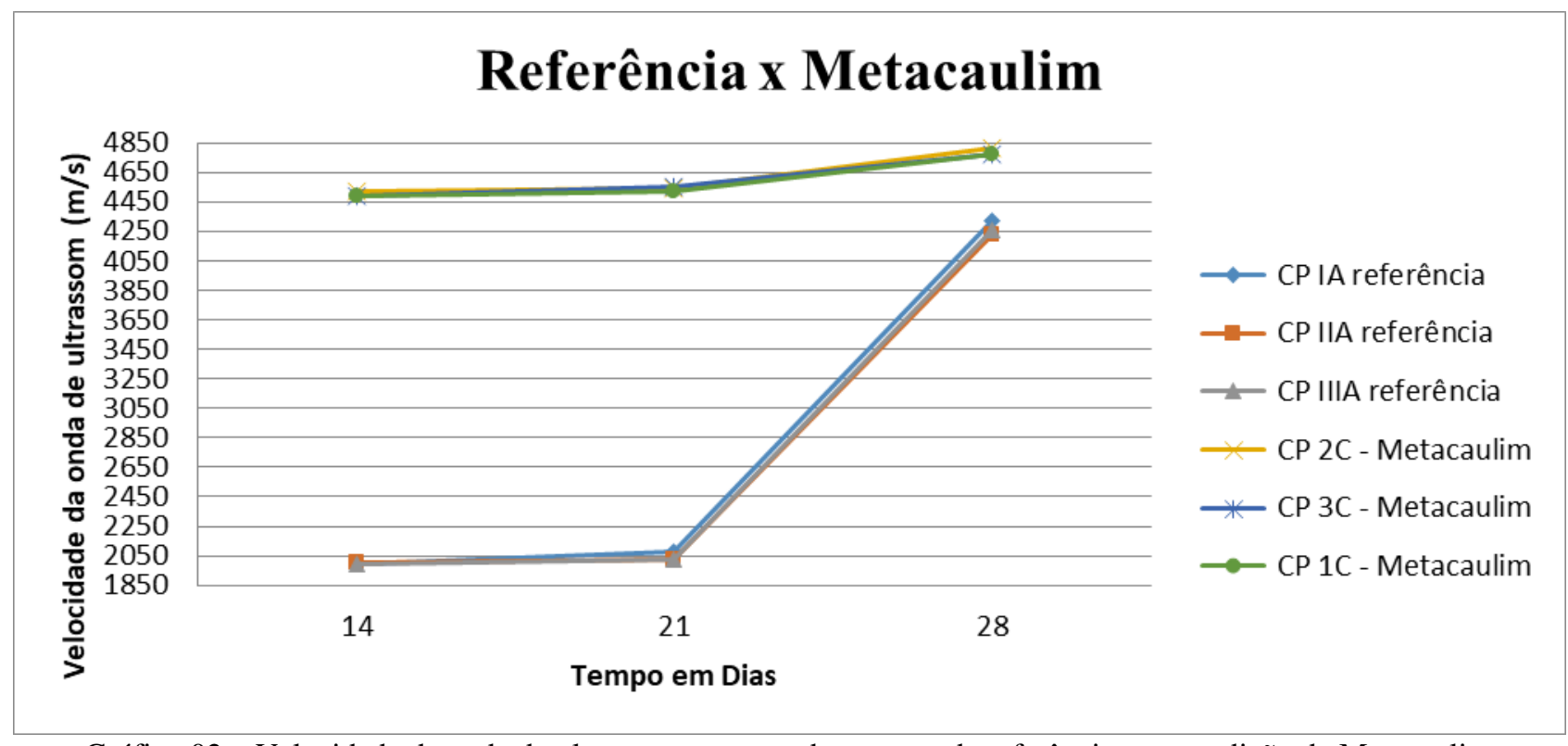

Gráfico 02 - Velocidade da onda de ultrassom x tempo dos corpos de referência e com adição de Metacaulim Fonte: Os autores (2019). 


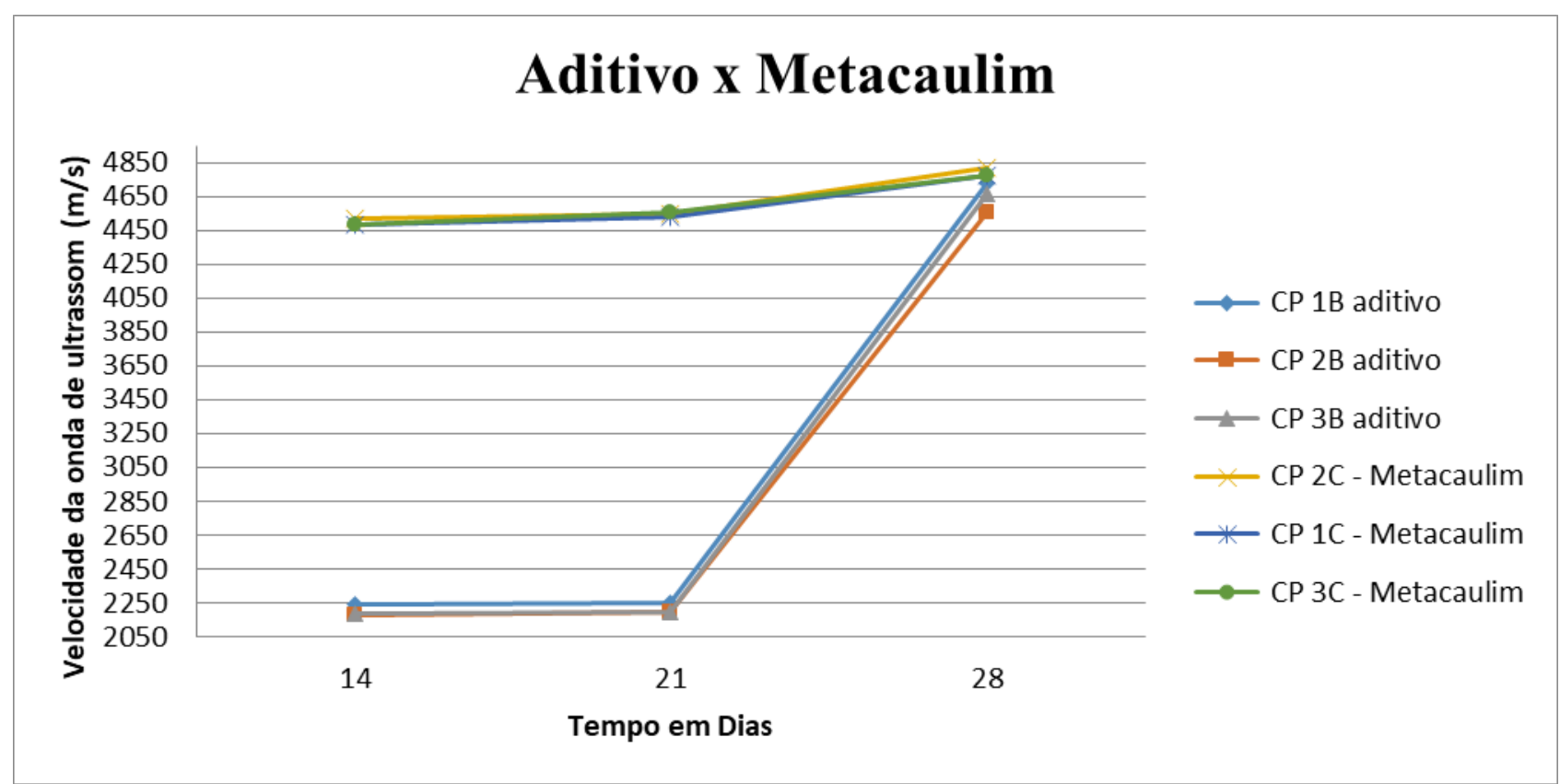

Gráfico 03 - Velocidade da onda de ultrassom x tempo dos corpos com aditivo e com adição de Metacaulim Fonte: Os autores (2019).

Analisando o ensaio de ultrassom observou-se que todas as amostras tiveram aumentos nas velocidades de ultrassom. $\mathrm{O}$ grupo de Metacaulim desde o sétimo dia já havia obtido velocidades maiores que os outros grupos, isto pode ser explicado pela reação pozolânica, pois os produtos das reações cimentíceas do Metacaulim são capazes de refinar os poros do concreto (MEHTA E MONTEIRO, 2014), reduzindo então os vazios, tornando-o um material mais compacto e facilitando a passagem das ondas.

De acordo com Rincon et al (1998) os concretos que apresentam velocidade de ultrassom superiores a $4500 \mathrm{~m} / \mathrm{s}$ são classificados como excelentes, portanto, as amostras de concreto com Metacaulim e aditivos são enquadradas como excelente em função dos valores de ultrassom e o grupo de referência como um bom concreto, por apresentarem a velocidade de ultrassom entre $3500 \mathrm{~m} / \mathrm{s}$ e $4500 \mathrm{~m} / \mathrm{s}$.

\subsection{Ensaios de resistência à compressão axial}

No ensaio de resistência à compressão axial, o grupo que apresentou maior resistência foi o concreto com adição de Metacaulim, atingindo resistência superiores à $28 \mathrm{MPa}$, conforme tabela 03 e gráfico 04.

Tabela 03 - Ensaio de resistência à compressão - NBR 5739

\begin{tabular}{c|c|c}
\hline \multicolumn{2}{c}{ NBR 5739 - Ensaio de compressão de cp cilíndricos - 28 dias - 26/04/2019 e 17/05/2019 } \\
\hline Corpo de Prova & Carga ruptura (kgf) & Tensão ruptura (MPa) \\
\hline CP IA referência & 11280,00 & 14,1 \\
\hline CP IIA referência & 13970,00 & 17,4 \\
\hline CP IIIA referência & 14990,00 & 18,7 \\
\hline CP 1B aditivo & 18540,00 & 23,1 \\
\hline CP 2B aditivo & 19130,00 & 23,9 \\
\hline CP 3B aditivo & 20110,00 & 25,1 \\
\hline CP 1C - Metacaulim & 25830,00 & 32,3 \\
\hline CP 2C - Metacaulim & 22930,00 & 28,6 \\
\hline CP 3C - Metacaulim & 26840,00 & 33,5 \\
\hline
\end{tabular}

Fonte: Os autores (2019). 


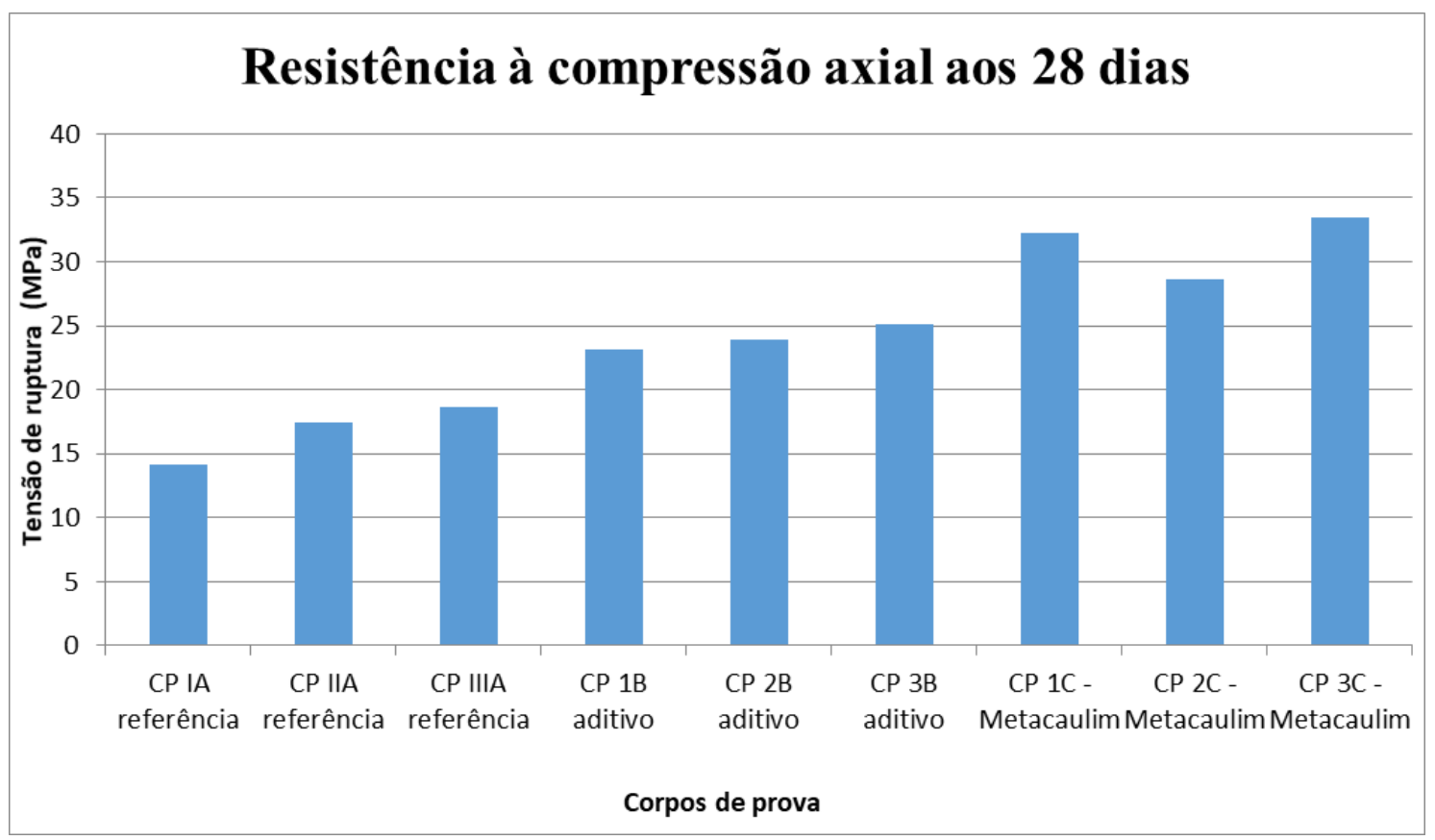

Gráfico 04 - Ensaio de resistência à compressão axial Fonte: Os autores (2019).

O aumento de resistência ocorre em função de um somatório de consequências do uso do Metacaulim. Segundo MEHTA E MONTEIRO (2014), os aditivos pozolânicos conferem aumento de resistência em função do refinamento dos poros do concreto, a reação pozolânica e formação adicional de C-S-H.

\subsection{Relação do ensaio de resistência à compressão axial e ultrassom}

Analisando o gráfico 05 de linha de tendência da resistência à compressão axial e a velocidade da onda de ultrassom é possível inferir a relação entre as duas variáveis, uma vez que os valores de tensão de ruptura apresentaram proporcionalidade à velocidade de onda ultrassônica, demonstrado pela função potencial entre as duas variáveis no valor de $\mathrm{R}^{2}=0,7811$. Segundo MOHAMAD ET AL (2015) e segundo análise do gráfico, é possível concluir ainda que quanto maior o valor da tensão de ruptura, maior será a relação entre esta variável e o valor da velocidade de onda de ultrassom.

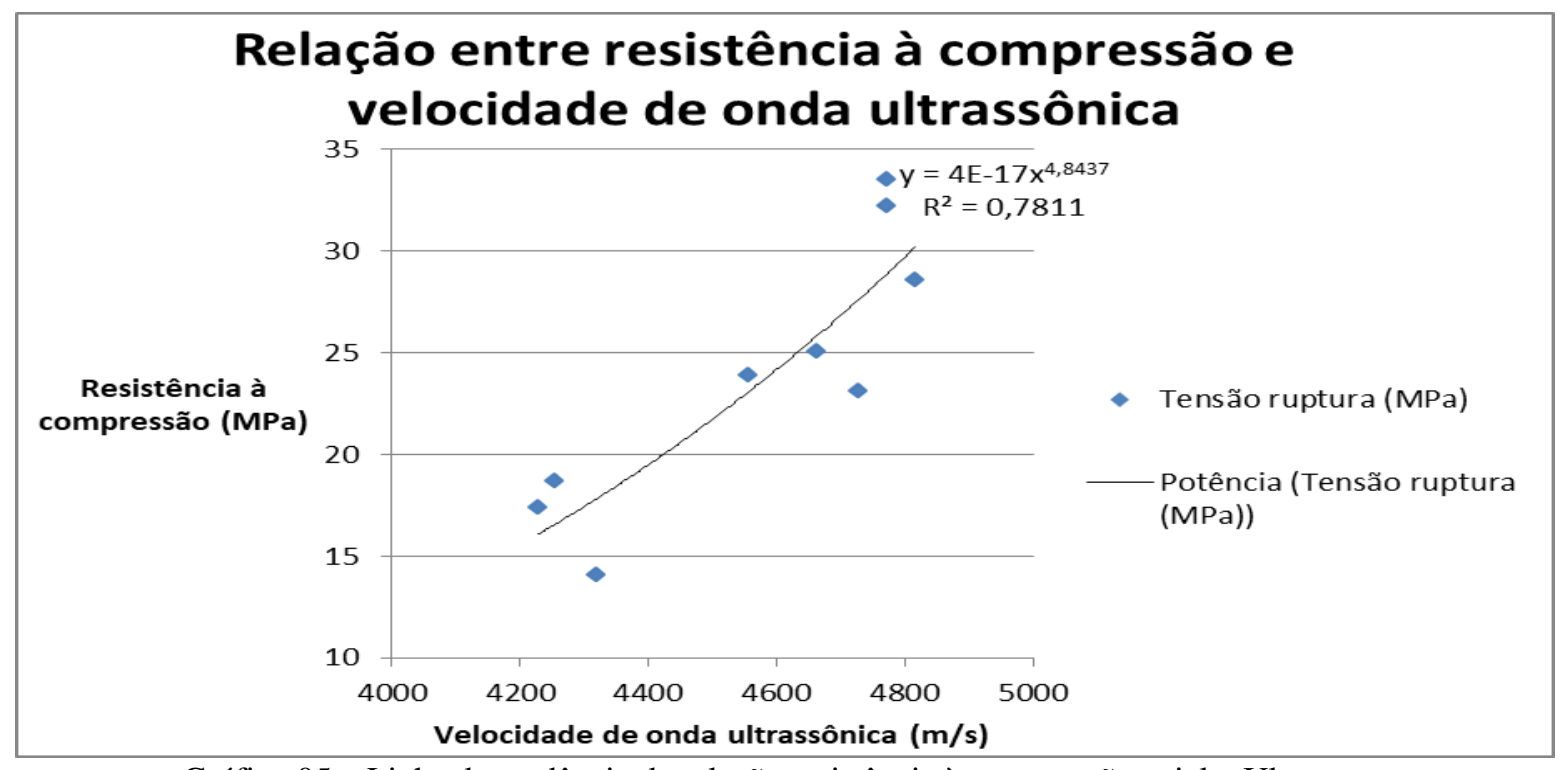

Gráfico 05 - Linha de tendência da relação resistência à compressão axial x Ultrassom Fonte: Os autores (2019). 
Segundo EVANGELISTA (2002) obsersou-ve que o tipo do cimento e a dimensão dos agregados são fatores que influenciam na relação do ultrassom e resistência à compressão. Neste estudo, verifou-se que as amostras com Metacaulim apresentaram maior tendência linear na função potencial, $\mathrm{R}^{2}=0,9469$, como verificado no gráfico 06 , podendo inferir que amostras ou estruturas que apresentem tal insumo, terão maior assertividade para inferir resultados de suas resistências através do ensaio de ultrassom.

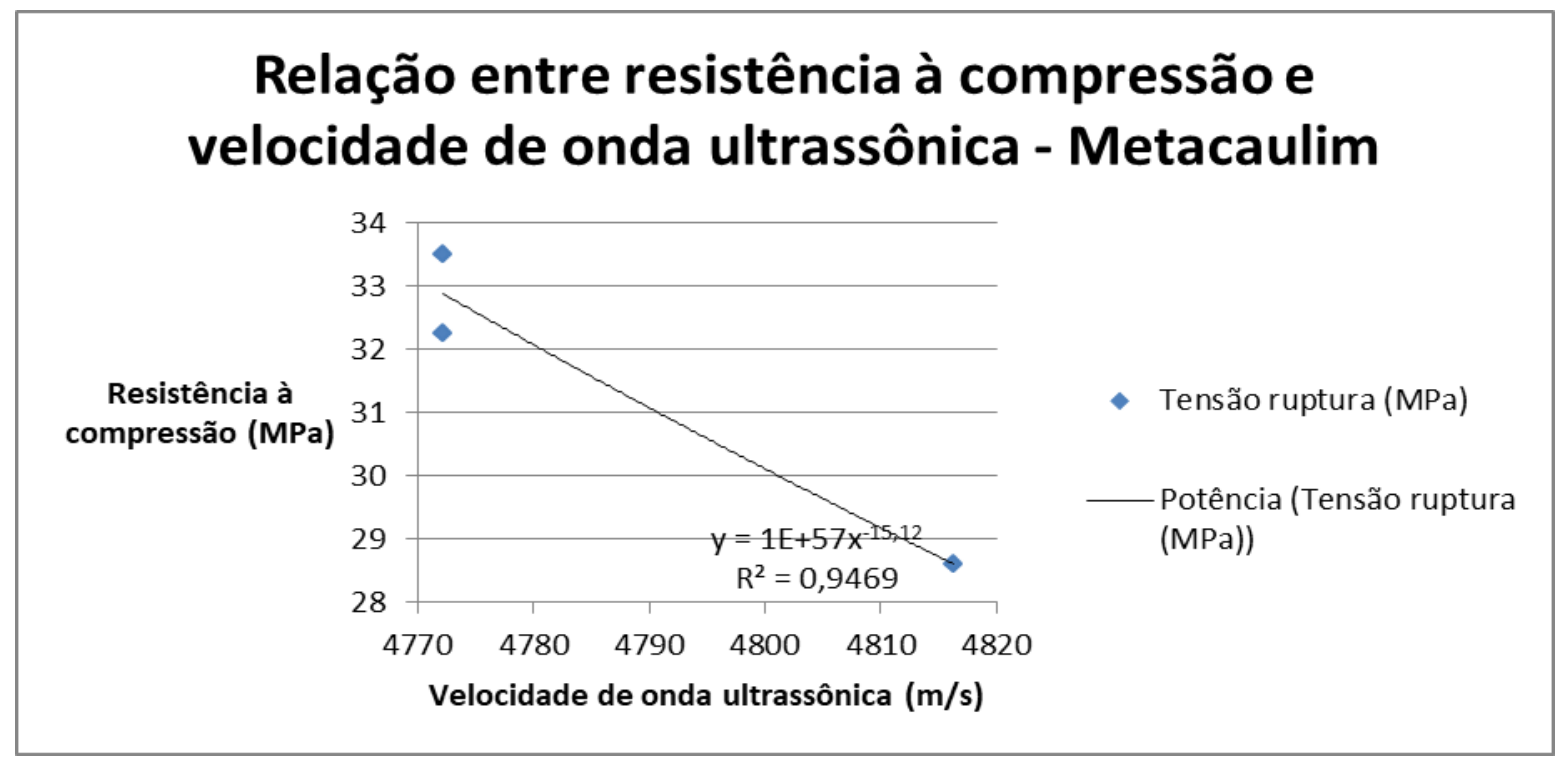

Gráfico 06 - Relação Resistência à compressão axial x Ultrassom amostra com Metacaulim Fonte: Os autores (2019).

\section{CONSIDERAÇÕES FINAIS}

O presente trabalho teve por finalidade verificar a correlação dos resultados do ensaio não destrutivo de ultrassom e a compressão axial, através de análise dos resultados da influência de dois diferentes teores de aditivos, variando a quantidade de água e adicionando o Metacaulim na composição de um concreto. Desta forma, foi analisado o comportamento dos corpos de prova no que se refere à resistência no estado endurecido.

Através dos resultados dos ensaios de ultrassom e compressão axial, ficou evidente a melhoria das propriedades reológicas dos concretos quando dosados com aditivo superplastificante e o acréscimo de Metacaulim, com resultados satisfatórios quando comparados com a dosagem de referência.

Além disso, foi evidenciado que os corpos de prova com Metacaulim, em sua média, apresentaram os maiores valores de massa quando aferidos e as maiores velocidades de ultrassom, o que pode ser explicado devido ao preenchimento dos vazios e pelo refinamento da estrutura dos poros, o que tornou o material mais compacto, proporcionando uma maior facilidade para a transmissão das ondas e aumento da resistência à compressão axial.

Desta forma, analisando a equivalência dos resultados dos ensaios de ultrassom e de compressão axial é possível estabelecer correlação entre os mesmos e provar que o ensaio de ultrassom pode ser utilizado como medida indireta da resistência do concreto. Logo, por se tratar de um ensaio de menor complexidade e impactos à estrutura, o ultrassom é recomendado para a aferição de resistência à compressão axial e poderá auxiliar no diagnóstico precoce de patologias, possibilitando uma maior durabilidade das estruturas. 


\section{REFERÊNCIAS}

ALVES, L. A; CAVALCANT, B. H. O; LAURSEN, A; RAMOS, M. V; TENÓRIO, L. A. B. Análise da Ingluência do Aditivo Superplastificante na Qualidade do Concreto. Universidade Federal de Campina Grande.

ASSOCIAÇÃO BRASILEIRA DE NORMAS TÉCNICAS (ABNT). NBR 5738. Concreto - Procedimento para moldagem e cura de corpos de prova. Rio de Janeiro, 2015.

ASSOCIAÇÃO BRASILEIRA DE NORMAS TÉCNICAS (ABNT). NBR 5739. Concreto - Ensaio de compressão de corpos de prova cilíndricos. Rio de Janeiro, 2018.

ASSOCIAÇÃO BRASILEIRA DE NORMAS TÉCNICAS (ABNT). NBR 8802. Concreto Endurecido - Determinação da velocidade de propagação de onda ultra-sônica. Rio de Janeiro, 2013.

ASSOCIAÇÃO BRASILEIRA DE NORMAS TÉCNICAS (ABNT). NBR 11768. Aditivos Químicos Para Concreto de Cimento Portland - Requisitos. Rio de Janeiro, 2011.

BARATA, M. S. Estudo de Viabilidade Técnica e Econômica de Produção de Concreto de Alto Desempenho com os Materiais Disponíveis em Belém Através do emprego de Adições de Sílica Ativa e Metacaulim. Porto Alegre, Rio Grande do Sul.

BASTOS, A. P. O. Análise da Influência de Aditivos Superplastificantes no Comportamento de Pastas de Cimento Portland Com e Sem Adição de Fíler Calcário. Porto Alegre, 2016.

CARMO, J. B. M. C. Análise Comparativa do Desempenho de Concretos Compostos com Sílica Ativa em Metacaulim Face à Resistência Mecânica e à Viabilidade Econômica. Curitiba, 2006.

COSTA, R. M. Análise de propriedades mecânicas do concreto deteriorado pela açãode sulfato mediante utilização do UPV. Tese - Universidade Federal de Minas Gerais. Belo Horizonte, 2004.

EVANGELISTA, A. C. J. Avaliação da Resistência do Concreto Usando Diferentes Ensaios Não Destrutivos. Tese Universidade Federal do Rio de Janeiro, COPPE, 2002.

GASPARINI, L. Avaliação da Influência do Aditivo Plastificante Multifuncional Redutor de àgua na Resistência Mecânica do Concreto Dosado Pelo Método ABCP. Lajeado, 2017.

HAACH, V. G.; RAMIREZ, F. C. Qualitative assessment of concrete by ultrasound tomography. Construction and Building Materials 119, p. 61-70, 2016.

IBI, Instituto Brasileiro de Impermeabilização. Manual de Utilização de Aditivos Para Concreto Dosado em Central. [S.I.: s. n.], 2015. 32. P. v. 1.

ISAIA, G.C Concreto: Ciência e Tecnologia. Editora IBRACON. São Paulo: IBRACON, 2011.

MEDEIROS, A. Aplicação do Ultra-som na Estimativa da Profundidade de Fendas Superficiais e na Avaliação da Eficácia de Injeções em Elementos de Concreto Armado. Florianópolis: Universidade Federal de Santa Catarina, 2007.

MEDINA, E. A. Pozolanicidade do Metacaulim em Sistemas Binários Com Cimento Portland e Hidróxido de Cálcio. São Paulo, 2011.

MENEZES, C. M. T. Concreto Auto-Adensável Utilizando Metacaulim e Pó de Pedra Como Adições Minerais. Recife, 2006.

MeThA, P. K.; MONTEIRO, P.J.M. Concreto. Microestrutura. Propriedades e Materiais. São Paulo: IBRACON. 2014. 
MOHAMAD, G.; CARMO, P. I. O.; OLIVEIRA, M. J. D. Métodos combinados para a avaliação da resistência de concretos. Revista Matéria.Santa Maria; RS. ISSN 1517-7076 artigo 11579, pp.83-99, 2015.

MORAES, J. S. L. J. Aditivo Para Concreto. Faculdade de Ciências Sociais e Agrárias de Itapeva. Revista FAIT. 2014.

NAIK, T. R.; MALHOTRA, V. M.; POPOVICS, J. S. The Ultrasonic Pulse Velocity Method, CRC handbook on nondestructive testing of concrete, Tarun R. Naik and V M MALHOTRA. eds, CRC Press, 2004.

NEVILLE, A. M. Propriedades do Concreto; tradução Salvador E. Giamusso. São Paulo: PINI, 1982.

PEREIRA, E.; MEDEIROS, M. H. F. Ensaio de "Pull Off" Para Avaliar a Resistência à compressão do concreto: Uma Alternativa aos Ensaios Normalizados no Brasil. Rev. IBRACON Estrut. Mater. Vol 5. São Paulo, 2012.

RINCÓN, O. T.; CARRUYO, C. A.; HELENE, P.; DÍAZ, I. Manual de inspeccion, evaluacion y diagnostico de corrosion em estruturas de hormigon armado. DURAR: Red Temática XV. B. Durabilidad de la Armadura Programa Iberoamericano de Ciência y Tecnologia para el desarrollo, 1998.

ROCHA, G. G. N. Caracterização Microestrutural do Metacaulim de Alta Reatividade. Belo Horizonte, 2005.

SOEIRO, J. M.; COSTA, S. S.; SILVA, A. P.; CHAHUD, E. Ensaio não destrutivo - Ensaio de ultrassom e pacômetro na avaliação da qualidade do concreto armado. Congresso Técnico Científico da Engenharia e da Agronomia. Maceió, 2018.

WHITEHURST, E. A. Evaluation of concrete properties from sonic tests. Detroit: American Concrete Institute, 1966. 